\title{
Continuous assessment of the resilience of critical infrastructure: the Nantes ring road flood experimental scenario
}

\author{
Hélène Dolidon ${ }^{1, a}$, Lionel Lilas ${ }^{2}$, Daouda Kamissoko ${ }^{3}$ \\ ${ }^{1}$ CEREMA, MAN, 9 Rue René Viviani, 44200 Nantes, France \\ ${ }^{2}$ DIRO, l'Armorique, 10 rue Maurice Fabre, 35031 Rennes, France \\ ${ }^{3}$ IMT Mines Albi, University of Toulouse, Campus Jarlard, 81013 Albi, France
}

\begin{abstract}
Flooding is frequent on the Nantes ring road and disrupts users dependent on this mode of transport directly or indirectly. To deal with them, the road operator has defined preventive and curative measures based essentially on the flow of the river involved in the submergence of the roadway. The RESIIST (Resilience of Interconnected Infrastructures and Systems) research project aims to develop a methodology and tools to assess the resilience of Critical Infrastructures (within the meaning of European Directive 2008/114/EC), of which we find the ring road. In order to test them, a scenario will be used to simulate the events likely to cause flooding, characterise the disturbances caused by these events and the interactions with adjacent road infrastructures and present a decision aiding based on the road operator's criteria. RESIIST can contribute to improving the resilience of critical infrastructures by enabling stakeholders to continuously monitor data from the context, to interpret them and deduce the disruption's risks on infrastructure and territory and finally to benefit from proposals for solutions adapted and corresponding to their decision criteria. More modestly, this scenario could serve as a support in discussions on possible work concerning the ring road and the crisis management protocols.
\end{abstract}

\section{Introduction}

The RESIIST (Resilience of Infrastructures and Interconnected Systems) research project, funded by the French ANR (National Research Agency), aims to develop a methodology and tools to assess the resilience of critical infrastructures. The directive 2008/114 / CE3 thus defines a critical infrastructure as " a point, a system or part of it, located in the Member States, which is essential to maintain the vital functions of society, health and safety. , the safety and the economic or social well-being of citizens, and the shutdown or destruction of which would have a significant impact in a Member State due to the failure of these functions."

The objective of the project is based on the following definition of resilience: "the ability of a system or society to be able to cope quickly with a disaster or sudden crisis and to restore the capacity to function. as quickly as possible" (Center for Security Studies, 2009), and is to offer infrastructure players different strategies to: (i) better anticipate events, (ii) restore as quickly as possible a level of service deemed satisfactory, and (iii) make their infrastructure, and the territory on which it is likely to have an impact, less affected by crises.

In order to test this method and the tools developed, three scenarios were selected, including the flooding of the Nantes ring road (see photo 1).

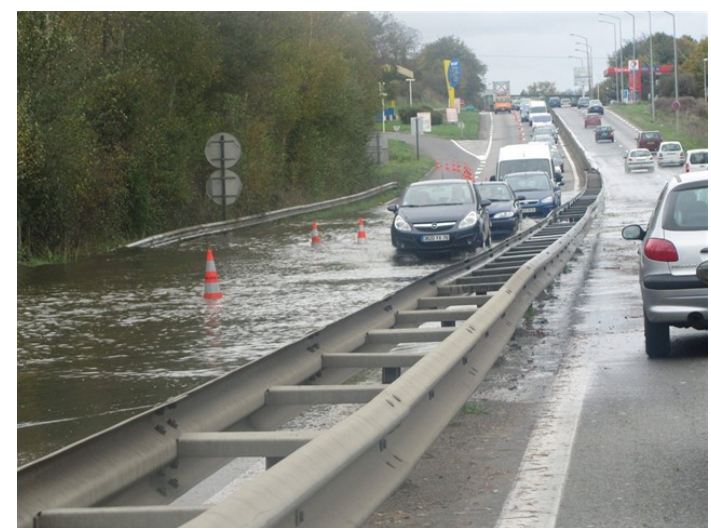

Photo 1. Floods on the Nantes ring road in 2010 (DIRO)

This scenario should allow simulate events likely to cause flooding, characterize the disturbances caused by these events and the interactions with adjacent road 
infrastructures, present a decision aiding based on the operator's criteria.

Several difficulties were encountered: understanding the complexity of the causes of flooding, defining an "acceptable" functioning allowing to serve as a reference to assess the level of degradation of the Critical Infrastructure (CI) and finally consider the subjectivity of the actors.

To show the main results obtained during the realization of this scenario, we will proceed in four stages:

- a first stages will be devoted to the presentation of the current situation,

- a second stage will focus on the analysis of the correlations between hazards and flood risks,

- a third stage will be devoted to the analysis of the impact of floods on the traffic of the ring road and the adjacent road infrastructures,

- and finally, a fourth stage will focus on possible ways of improving the treatment of these disturbances.

\section{Current situation}

The Nantes ring road ( $\mathrm{RN} 844$ ) is 42 kilometers long.

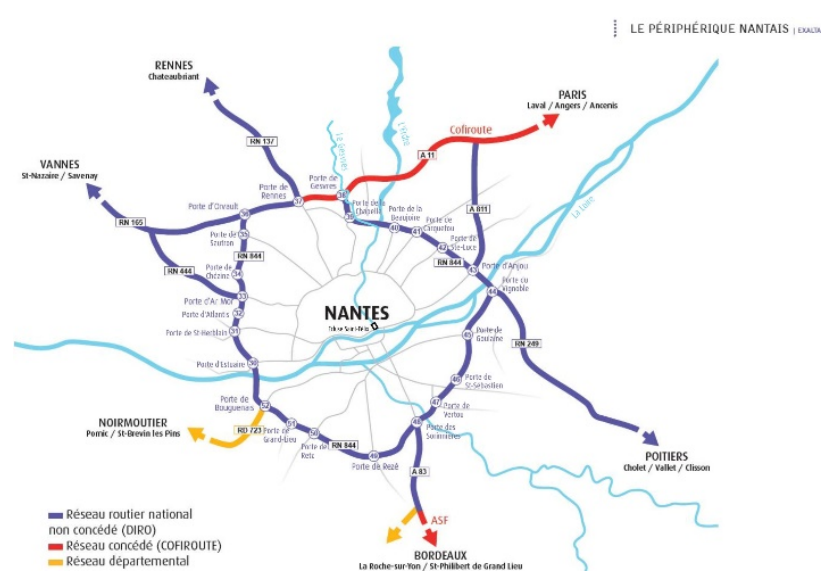

Figure 1. Map of the Nantes ring road and its operators

It was gradually developed by several contracting authorities (State, Departmental Council, Agglomeration of Nantes) between 1972 and 1994 (DREAL - Regional Directorate for the Environment, Planning and Housing, 2014).

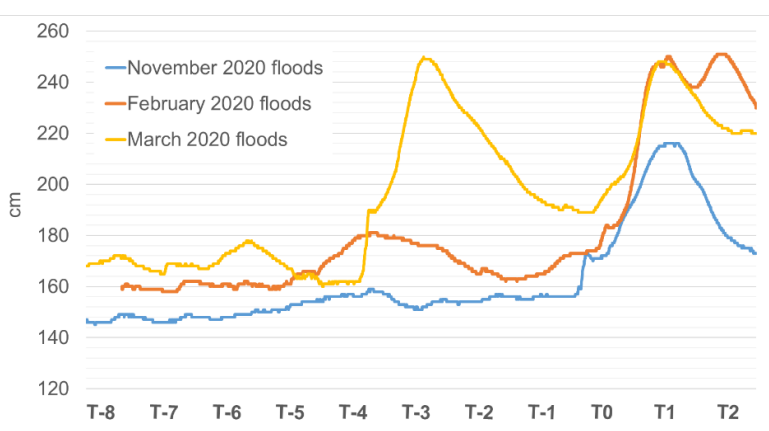

Figure 2. Comparison of the heights of the Gesvres at the Jonelière station $(\mathrm{T} 0=1$ st day of flooding of the ring road)
Today, it is classified in the structuring national road network (ministerial decree of December 9, 2005) and it is operated by the Interdepartmental Direction of Western Roads (DIRO), except on a portion to the north that is operated by Cofiroute (see Figure 1). It supports traffic levels, on an annual daily average of between 61,000 and 104,000 vehicles (depending on the section). The roadway of the Nantes ring road is regularly flooded, to the northeast. The main causes identified are the episodes of heavy precipitation that lead to the overflow of the nearby "Gesvres" river and the rise of water tables, but also the vulnerability of the roadway, probably due to historical construction choices, which are more profitable in the short term than on long term (Kerisel et al., 1978). The consequences of these floods are obvious in terms of longer travel time and increased insecurity (see Photo 1).

To cope with these regular floods, the DIRO must close the ring road to traffic, partially or totally (depending on the extent of the submersion of the roadway), between "Porte de la Chapelle"and "Porte de la Beaujoire, (which are two ring road interchanges) and sets up alternative routes (called: "S" alternative routes) which have domino effects on adjacent road infrastructures (DIRO, 2015).

\section{Correlations between hazards and the risk of flooding}

The DIRO has a measuring station (La Jonelière) to check the Gesvres river's water level on the edge of the outer ring road. Different episodes during which the ring road was flooded have been compared and show a good correlation between the Gesvres water level and the flooding on the ring road (see figure 2). In this way, DIRO has been able to determine the main alert ratings:

- $\quad$ around $160 \mathrm{~cm}$ : put in observation;

- $203 \mathrm{~cm}$ : water arrives on the right lane of the outer ring road;

- $210 \mathrm{~cm}$ : water arrives on the left lane of the outer ring road;

- $228 \mathrm{~cm}$ : water arrives on the left lane of the inner ring road;

- $230 \mathrm{~cm}$ : water arrives on the right lane of the inner ring road. 
However, in order to better understand the causes of flooding, and possibly better anticipate or manage them, other factors were analysed (see figure 3 ). Events prior to the water rise at the Jonelière station were first taken into account such as the Gesvres flood upstream (at the Treillères station), rainfall and soil saturation. These three events cause or aggravate the flooding of ring road.

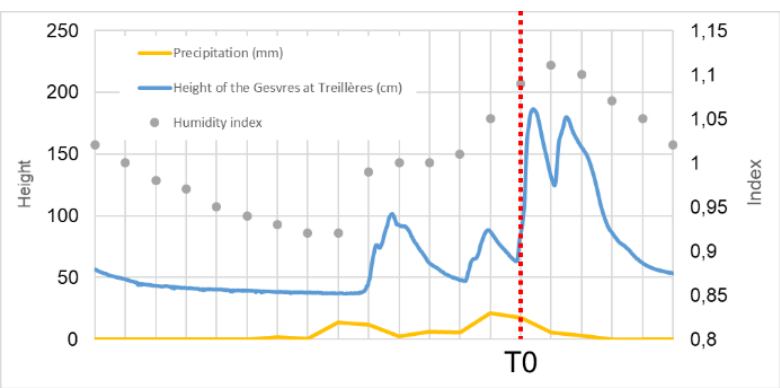

Figure 3. Flood factors: February 2020

In addition, the flow downstream conditions of Gesvres were also studied; we have assumed that the Erdre water height (the Erdre is the river into which the Gesvres connects) could prevent the flow of the Gesvres and thus increase the possibility of a flood.

Indeed, Figure 4 shows that every time the ring road was flooded in the last two years, the Erdre was flooded too. To confirm this hypothesis, the flow factors of the Erdre downstream were also studied. The Erdre level is indeed partly ensured by a lock. However, the operation of the lock, which makes it possible to raise or lower the Erdre level, is itself dependent on several factors: the Loire level, timing of the tide and of course the users interests (ex: people living in barges which stay on the water) and the fauna. Thus, it is not possible to use the lock if the Loire level (the river into which the Erdre flows) is too high. It is not possible to lower the Erdre level too much either, otherwise the boats could run aground, fishes could be disturbed in a way which would not be accepted. Eventually, it is not possible to do so at any time of the day because of the tide whose effects are visible as far as Nantes. Thus, the study of the correlations between the events and the risk of flooding of the ring road shows that the causes are very complex and that they would require monitoring tools.

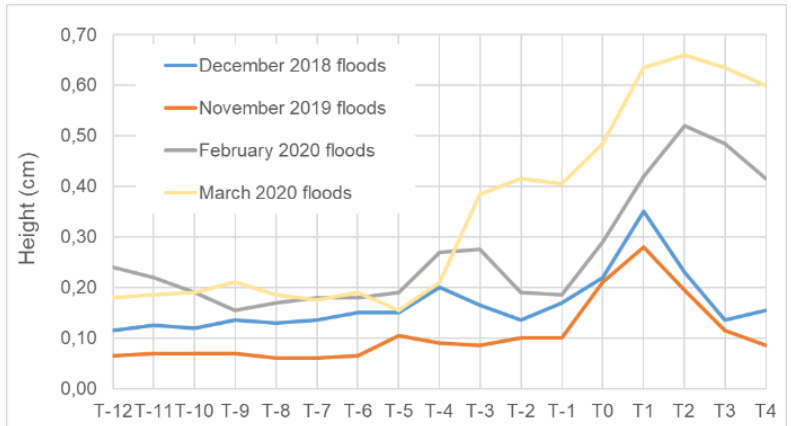

Figure 4. Comparison of the heights of the Erdre $(+4.34 \mathrm{~m} \mathrm{NGF}$ 69 ) at the Port-Jean station (upstream of the confluence with the Gesvres)

\section{Impact analysis of flooding on both ring road and adjacent road infrastructure traffic}

\subsection{Research methodology}

First, to characterize the ring road transit functions performance, we need to compare traffic situations with or without flooding. A total of seven periods were studied: five with flooding and two without flooding. The traffic data was considered the most relevant to illustrate the performance of the road, whose main function is the transit of users, and, among this traffic data, the speeds were selected to corroborate the rule that is used to determine traffic jams in the main cities in France. This rule judges that, for a regulated speed between 70 and $90 \mathrm{~km} / \mathrm{h}$ :

- Traffic is fluid if the speed is greater than $50 \mathrm{~km} / \mathrm{h}$,

- Traffic is dense if the speed is between 30 and $50 \mathrm{~km} / \mathrm{h}$,

- Traffic is congested if the speed is less than $30 \mathrm{~km} / \mathrm{h}$.

This indicator has happened to be a means of calculation simple. Nevertheless, it can be subject to different points of view depending on the operators and the equipment levels. In addition, it does not take into account the geographic and temporal extent of the congestion as well as its "severity", such as the delay experienced by users (BUISSON et al., 2010).

In order to take into account the changes in speed limits of the Nantes ring road, the ratio between the average speeds practiced and the authorized maximal speed at each section of the ring road, has been calculated every 6 minutes. The final results are considered as a good indicator of the ring road's performance.

The next step was to define a reference state, deemed "acceptable" for maintaining transit functions within the territory, which would then serve to illustrate the differences between a period when the ring road is closed and a period when it is not closed. To define it, the week of December 3 to 9, 2018 was chosen based on the following criteria (COHEN et al., 2014): absence of disturbances (works), absence of disturbed weather conditions (no flooding) and absence of school vacations.

Finally, the last step was to study the interactions of the ring road with the urban infrastructure system so as to be able to better assess the resilience of the territory, in case of ring road flooding. "In urban resilience systems, the critical infrastructure systems, such as buildings, transportation networks, energy, and water grids (utilities), represent principal components in our society due to their indispensable role for the maintenance of critical societal functions. The potential destruction of critical infrastructures could weaken the whole defence and economic organization. In this context, the change and improvement of urban critical infrastructure systems have an opportunity to make cities more resilient today. » (Yang et al., 2020). Not all interactions with urban infrastructure have been studied, only an assessment of the capacity of the adjacent road network to absorb the traffic spin off due to the ring road closure, has been carried out.

To study the traffic on the urban network, the number of vehicles recorded at the various Measurement Points 
(PM) was considered to be the most relevant. The reference state, ultimately allowing traffic deferrals to be calculated, was modelled on the basis of the average flow rate per 15-minute period at PM in January 2020 (school vacation days excluded). This reference state allows us to have the average flow for each time slot based on the day of the week and the time of day. Some outliers or missing data have been manually corrected. Then, the flow rates were compared, for each PM located on the alternate routes, between the pre-set reference state and periods when the ring road was closed.

\subsection{Evaluation of ring road transit functions}

When flooding occurs, the ring road is closed between the "Porte de la Chapelle" and the "Porte de la Beaujoire" (see Figure 5). The results indicate that, normally, the ratio practiced / authorized speed is greater than $80 \%$ (users are traveling at more than $70 \mathrm{~km} / \mathrm{h}$ ), except during the morning and evening rush hour, on outer ring road (see figure 6). During the rush hours, users travel at a speed of between 15 and $40 \mathrm{~km} / \mathrm{h}$.

We consider this traffic to be "normal", at least "acceptable", since it is not due to particular events.
The same treatment was carried out during the school holidays. It result that the congestion is less important except at the gates of Anjou and Beaujoire. Then, with the same method, we characterized the degradation of the transit functions of ring road in the event of closure due to flooding. Thus, three metering stations are mainly impacted: Beaujoire, Batignolles and Carquefou, which is illustrated by a practiced speed / authorized speed ratio close to $0 \%$ (see Figure 7).

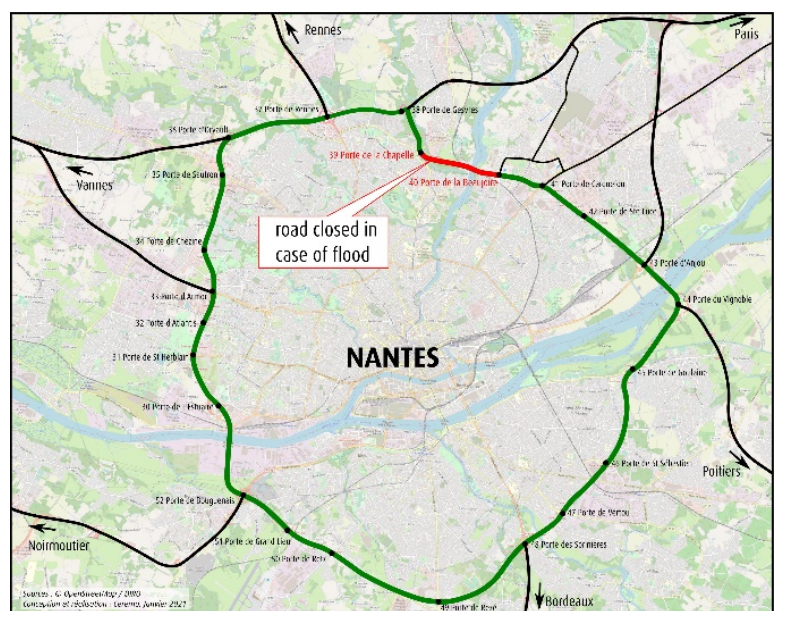

Figure 5. Map of flooding on the Nantes ring road

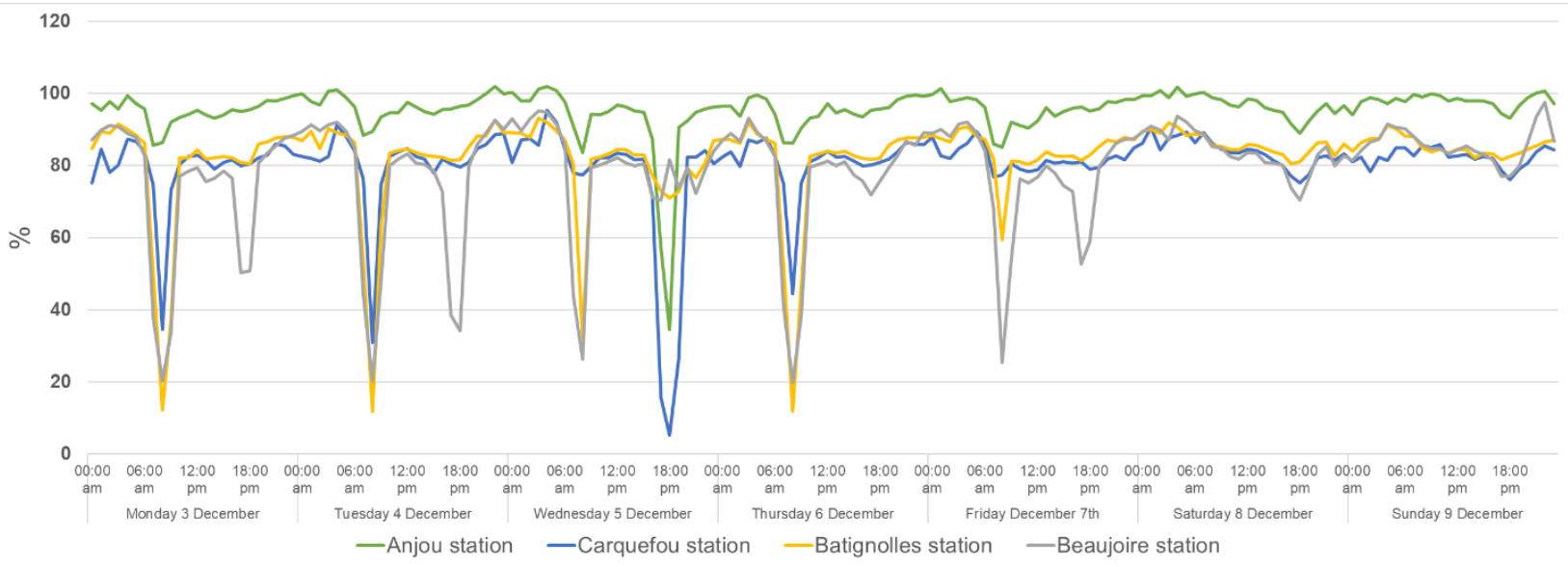

Figure 6. "Normal" operation of the Nantes outer ring road between the Anjou and Beaujoire gates

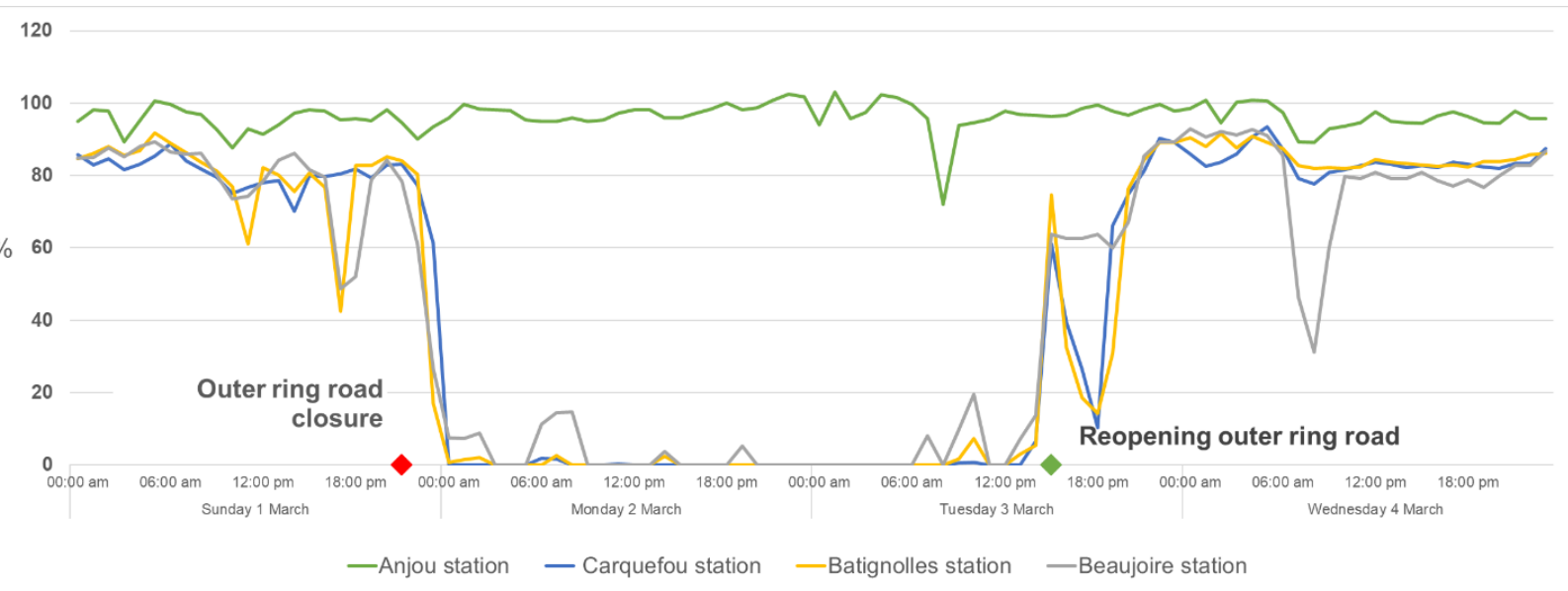

Figure 7. Operation disrupted by flooding of the Nantes outer ring road 


\subsection{Impact analysis on adjacent road infrastructure traffic}

When the ring road is closed to traffic due to flooding, two alternative routes (called $\mathrm{S}$ routes) can be activated (see Figure 8). These are detour routes, indicated for users by means of specific signs or messages on the already existing signs.

The outer ring road is flooded in first and requires the activation of the S6 route. This route follows the urban network of Nantes Metropole and the Cofiroute motorway network. The S5 route is activated when the inner ring road is closed as well and also uses the Nantes Metropole and Cofiroute network.

Traffic spin-offs on the Nantes mainland network were assessed by analyzing the flow rates at the measurement stations located on the alternative routes. Consequences on traffic conditions are measurable when the ring road is closed and it is even possible to spot the most impacted measurement points, such as PM 0818 (see Figure 9). The difference of number of vehicles at these measuring points varies between 5 and $35 \%$.

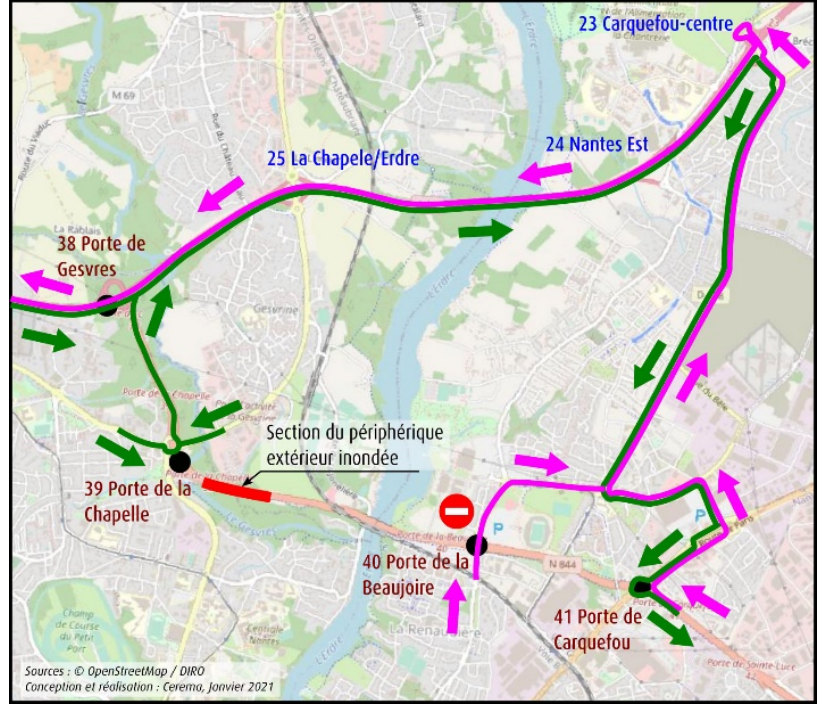

Figure 8. Map of alternative routes in the event of flooding of the East Nantes ring road (DIRO, 2015)

Consequences on Cofiroute network traffic conditions are also measurable in both directions of traffic, more than 1,000 vehicles from 8 a.m. to 9 a.m. on Monday March 2 (see Figure 10), in a proportion of $92 \%$ of Light Vehicles (Light Vehicles) and 8\% Heavyweight (PL).

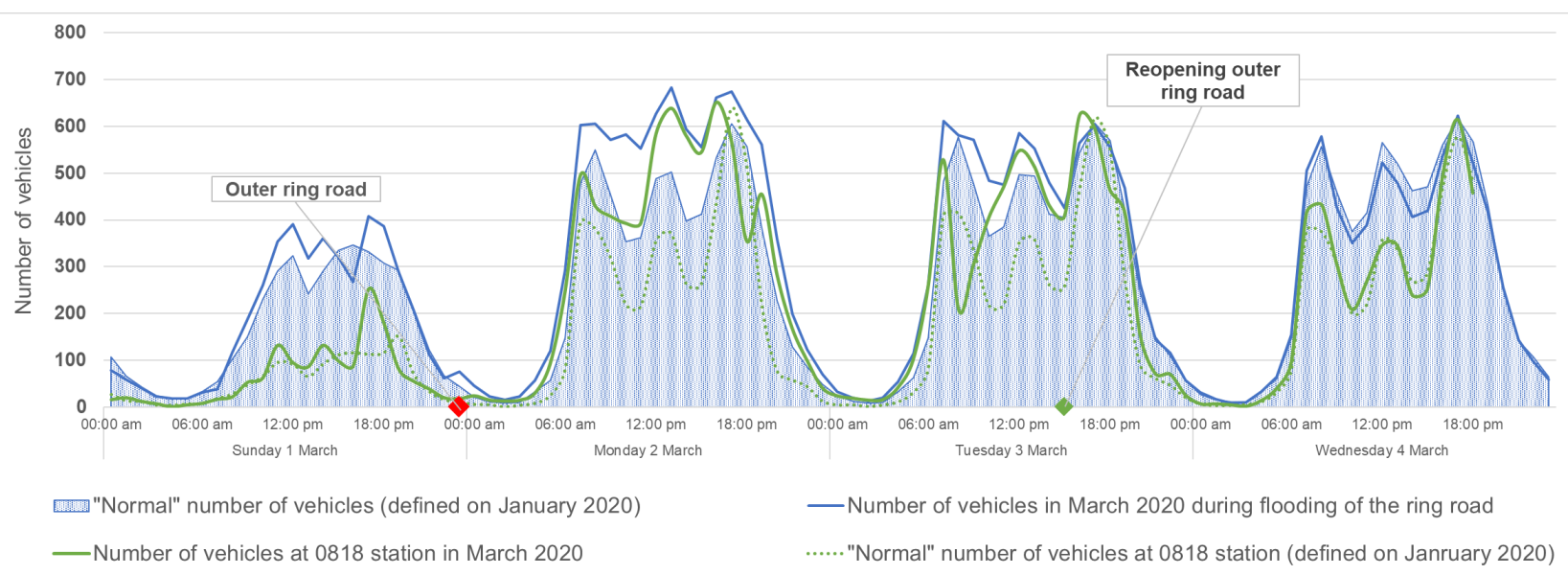

Figure 9. Comparison of average flows (calculated over January 2020) and flows from March 2020 at measurement points on the Nantes Metropole network located on the S6 route

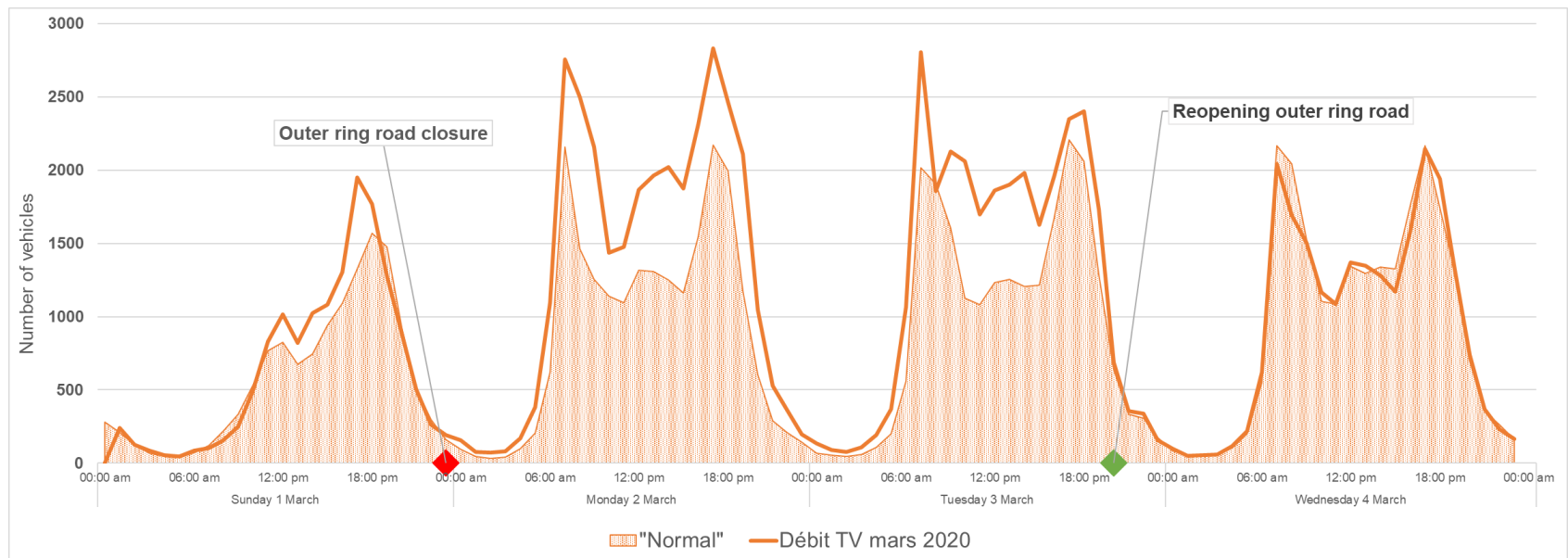

Figure 10. Comparison of average flows (calculated over January 2020) and flows from 1 to 4 March 2020 at measurement points on the Cofiroute network located on the S6 route 


\section{Study of possible ways for improvement}

The flood scenario on the Nantes ring road must end with tests to improve the resilience conditions of the ring road and the territory in the event of flooding. In other words, we would like to find a way to strenghten various actors capacities to maintain the transit functions on the territory, in case of potential or proven risk of flooding.

A decision support grid has been created for the operator (see Table 1). It is based on the resilience diagram representing the performance of the infrastructure over time (see Figure 11).

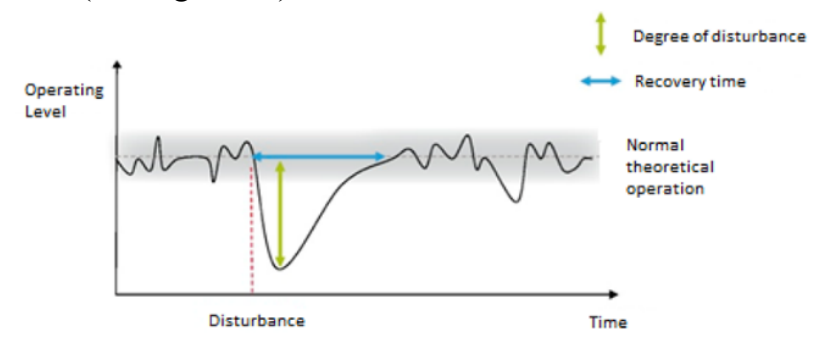

Figure 11. Short-term or Specific Resilience of an Urban Service to Disruption (TOUBIN et al., 2012)

By following the strategy aimed more particularly at improving resistance capacity, objectives, criteria and decisions were established for the operator. They are based on discussions within a technical working group on the floods of the Nantes ring road dated June 12, 2014 and the summary of which was produced by the Sea and Territories Departmental Direction (DDTM) from "LoireAtlantique". This working group had been set up after the Nantes ring road had been closed seven times because of flooding, including four times with total closures in both traffic directions. Initially, two alternatives were studied in this technical working group. The first one was to create a waterproof screen on both sides of the roadway. The second one was to accept flooding but to work on improving the way we close the ring road infrastructure.
The second alternative was chosen for reasons of profitability (the first solution cost was estimated at 16 million euros). It aims at reduce ring road closures's occurrence, better prevent them and better inform users, which was reflected in our study by the objectives cited in Table 1 .

It was hard to define one or several criteria to evaluate the gains obtained by the decision support because they differ according to the points of view. "Risk management in France should therefore focus on maintaining urban functions in the event of disruption and be reflected in the design, operation and governance of the city. But which functions should we take into account? Depending on whether you are an entrepreneur, an elected official, an engineer, a sociologist or an inhabitant, the answer varies widely. Should we maintain trade, education, waste treatment, communications between ministries, health, etc?" (Translated from TOUBIN, 2014).

In the first place, we have chosen to study three decision criteria, which are those of the operator of ring road: safety, profitability and user satisfaction. However, other points of view should be studied in the future.

The only way to act on events (objective 1) would be to promote the flow of Gesvres river (which is the cause of the floods on the ring road) either upstream by creating reservoirs, or downstream by lowering the level of the Erdre river thanks to the lock located a little further. The second solution may be difficult to carry out because the lock's level depends on the constraints of the users (in particular the inhabitants of the boats) but also on the Loire's level, which itself depends on both the upstream floods and the tide. To anticipate malfunctions (objective 2 ), the operator can decide to inform users about the risk of flooding or even device's closure, and encourage them to postpone their trips or to change their route. Finally, to prevent safety faults, and in particular accidents (objective 3 ), the operator can decide to prepare the appropriate operating measures by pre-positioning, for example, barriers and diversion signs.

Each of these objectives was then assessed against the three pre-defined decision-support criteria. The evaluation was conducted by interviewing the operator.

\begin{tabular}{|l|l|l|}
\hline \multicolumn{1}{|c|}{ OBJECTIVES } & \multicolumn{1}{|c|}{ CRITERIA } & \multicolumn{1}{c|}{ DECISIONS } \\
\hline $\begin{array}{l}\text { 1 - Act on events likely to impact the } \\
\text { operation of the Infrastructure (reduce } \\
\text { their occurrence) }\end{array}$ & $\begin{array}{l}\text { Safety } 50 \% \\
\text { User satisfaction } 50 \% \\
\text { Profitability } 0 \%\end{array}$ & Promote the flow of the Gesvres \\
\hline $\mathbf{2}$ - Anticipate malfunctions & $\begin{array}{l}\text { Safety } 10 \% \\
\text { User satisfaction } 85 \% \\
\text { Profitability } 5 \%\end{array}$ & Inform users (forecast) \\
\hline $\begin{array}{l}\mathbf{3} \text { - Preventing infrastructure security } \\
\text { flaws }\end{array}$ & $\begin{array}{l}\text { Safety } 100 \% \\
\text { User satisfaction } 0 \% \\
\text { Profitability } 0 \%\end{array}$ & Prepare operational measures \\
\hline
\end{tabular}

Table 1. Response of operator and resilience of the ring road to flooding

Then, we propose a decision aiding in the context of the Nantes ring road scenario such as linking: these decision criteria to monitored data (such as the water level or the number of vehicles) in real time so that we better anticipate the response. The benefits would be twofold. This would make it possible, on the one hand, to anticipate actions neither too late nor too early, which in the first case could lead to significant damage (especially in terms of 
human lives) and in the second case, a great users disappointment and unnecessary disruption to dependent services.

On the other hand, it would allow analysis of data interdependencies. These are effectively analysed within a model which makes it possible to relate them to the underlying issues and therefore to any contradictions between the objectives of the different stakeholders. This collaborative vision can only encourage finding better conditions to improve resilience regarding floods. " $A$ particular form of conflict that could both support and hinder the implementation of resilience is customary conflict [...]. The idea is that the same component can serve two distinct uses which can be contradictory, especially in a disturbance situation" (Translated from TOUBIN, 2014).

The improvement of the proposed decision support relies on the continuous evaluation of different contextual data and their modelisation, which makes it possible to adjust decisions more precisely over time and to make decisions in a wider territorial context.

\section{Conclusions}

The final results could be improved in the future. Improvements could include analysis of "levels of service", which is a more accurate indicator than speed to assess road performance, and of the number of transit users in the event of a ring road closure. More broadly, the cost of ring road closure and detour should be assessed and the possibility of correlating flood frequency with land use planning should be explored.

However, the results have already allowed to:

- take into account flooding phenomenon complexity and its consequences on the ring road, traffic degradation effects on both the ring road and adjacent road networks ;

- eventually propose useful solutions to the operator, based on the monitoring of traffic and hydrological data and its own criteria.

- Moreover, the interest of the scenario is also to feed the three scientific and technical components of the project:

- Data interpretation, which must make it possible to detect potential or proven malfunctions by interpreting the available data, whether it comes from the real-time situation or from knowledge capitalization

- Information modeling which will be used to contextualize information concerning actual or potential malfunctions and to diagnose the disturbances,

- Decision support, which objective is to use the diagnosis to accompany stakeholders towards a new, more stable and resilient state of equilibrium.

Beyond the scientific project, the scenario allows the different actors (forecasters, operators, town planners, governments...) to improve their collaboration using a new theoretical tool. This means that in the future, the scenario could participate in a wider debate on the interest (or not) of carrying out work on the ring road and/or reviewing land use planning. At the very least, the scenario could be a support for discussion in crisis management protocols and the developped tools will enable authorities to be better prepared. Indeed, they will be able to collect data from infrastructure context, interpret them through various indicators including technical, economic or environmental aspects and have a series of recommendations aimed either at limiting risks as much as possible, by reducing the vulnerability of the network, or at implementing back-up solutions if preventive measures could not be implemented in time or were not sufficient.

\section{References}

1. Buisson, C., Lesort, J.B. (2010). Comprendre le trafic routier - Méthodes et calculs. Guide méthodologique, Certu; $111 \mathrm{p}$.

2. Center for Security Studies (CSS). (2009). La résilience : un concept pour la gestion des catastrophes et crises. Analyses du CSS 60: 3p..

3. Cohen, S. et al (2017). Niveaux de services de circulation des voies structurantes d'agglomération circulées à 90 ou $110 \mathrm{~km} / \mathrm{h}$. Guide méthodologique Cerema, 74p.

4. DIRO (2015). Procédure inondation du périphérique Est de Nantes. Rapport interne, 6p.

5. DREAL (2014). RN844 Etudes du parti d'aménagement du périphérique nantais. Rapport interne, $367 \mathrm{p}$

6. Kerisel, J., Gonin, H. (1978). La traversée du marais de Gesvres par la rocade nord de la ville de Nantes. Revue générale des routes 6.

7. Toubin, M. (2014). Améliorer la résilience urbaine par un diagnostic collaboratif, l'exemple des services urbains parisiens face à l'inondation. Thèse de Géographie. Université Paris-Diderot - Paris VII

8. Toubin, M. et al. (2012). La résilience urbaine : un nouveau concept opérationnel vecteur de durabilité urbaine?. Développement durable et territoire Vol 3(1).

9. Yang, Z. et al., (2020) Assessing urban transport network resilience : a review on current approaches, Publication for ICoTSC) 